\title{
Study on Spacing Threshold of Nonsubmerged Spur Dikes with Alternate Layout
}

\author{
Xiaomeng Cao, ${ }^{1}$ Zhenghua $\mathrm{Gu}^{1}{ }^{1}$ and Hongwu Tang ${ }^{2}$ \\ ${ }^{1}$ College of Civil Engineering and Architecture, Zhejiang University, Hangzhou 310058, China \\ ${ }^{2}$ State Key Laboratory of Hydrology-Water Resources and Hydraulic Engineering, Hohai University, Nanjing 210098, China \\ Correspondence should be addressed to Zhenghua Gu; wise@zju.edu.cn
}

Received 21 September 2013; Accepted 19 November 2013

Academic Editor: Y. P. Li

Copyright (c) 2013 Xiaomeng Cao et al. This is an open access article distributed under the Creative Commons Attribution License, which permits unrestricted use, distribution, and reproduction in any medium, provided the original work is properly cited.

\begin{abstract}
This paper investigated the spacing threshold of nonsubmerged spur dikes with alternate layout to classify the impact scale of spur dikes. A mathematical model was built based on standard $k-\varepsilon$ model, finite volume method (FVM), and rigid lid assumption and was verified by experimental data. According to dimensional analysis, three indices, that is, $F_{r}$ (Froude number), $B / b$ (channel width to dike length), and $B / h$ (channel width to water depth), were identified as the influencing factors on the spacing threshold, based on which fifteen sets of conditions were simulated. The calculation results indicate that $B / h$ is the most influencing parameter on $S_{c} / b$ (spacing threshold to dike length), followed by $B / b$ and $F_{r}$. A dimensionless empirical formula of spacing threshold is fitted by multivariate regression. The results of four sets of additional conditions illustrate that the generalization of empirical formula is satisfactory and the precision of interpolation is higher than that of extrapolation. Furthermore, the spacing threshold of alternate spur dikes is generally smaller than ipsilateral spur dikes.
\end{abstract}

\section{Introduction}

Spur dikes are one of the most widely used structures in hydraulic engineering. They are introduced in rivers for channel regulation, flood prevention, and river diversion [13]. After the construction of spur dike, the original channel becomes narrow and the flow characteristics in the vicinity of spur dike are changed. In actual projects, spur dike exerts influence on river system usually in the form of groups $[4,5]$. These spur dikes (or groups) interact with each other in a certain range, beyond which they are independent [6]. They can be classified as large-scale and small-scale groups according to their interaction strength. When dikes have interaction with each other and play a role as whole, their combination can be considered as a spur dike group in smallscale, whereas a spur dike group in large-scale is comprised of single spur dikes or spur dike groups in small-scale with the long distance and few influence between each other $[7,8]$. The past research of spur dikes has mainly been focused on the effects of small-scale spur dike groups on local river ways, but rarely on the overall impact of large-scale spur dike groups on river systems [9-12]. However, the latter has vital significance to maintain river health, sustainable development and utilization of river systems, and integrated management of river basins [13-15]. Therefore, it is necessary to firstly find the cut-off point between small-scale and largescale groups. On this matter, several scholars have proposed the concepts of spur dike's recovery length or uninfluenced distance $[6,9,16]$, but so far, they did not obtain a clear conclusion. In our past research, the concept of spacing threshold has been proposed and used on nonsubmerged spur dikes with ipsilateral layout and same length [8]. In bank protection projects, however, alternate spur dikes arranged on both sides of the river are very common. Due to asymmetry, there are obvious differences in flow characteristics between alternate spur dikes and ipsilateral spur dikes [17]. Hence, it is necessary to conduct further investigations on the spacing threshold of alternate spur dikes.

In the current work, flume experiments considering nonsubmerged spur dikes with ipsilateral and alternate layout were conducted firstly. Then, a numerical model which depends on the standard $k-\varepsilon$ model, the finite volume method 

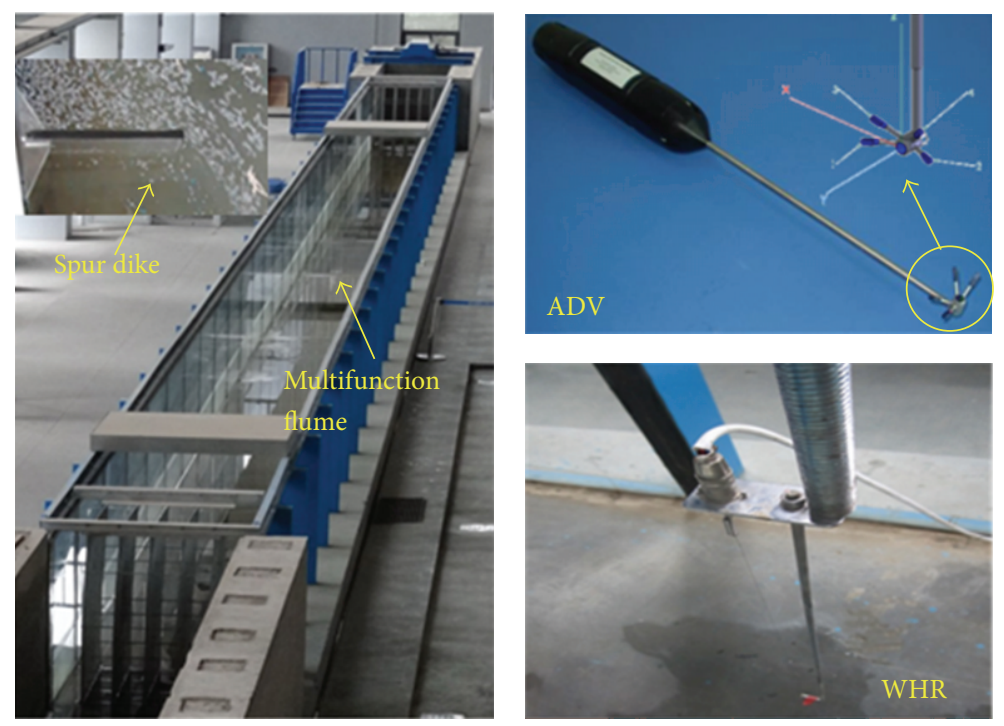

FIGURE 1: Multifunction flume and measuring instruments.

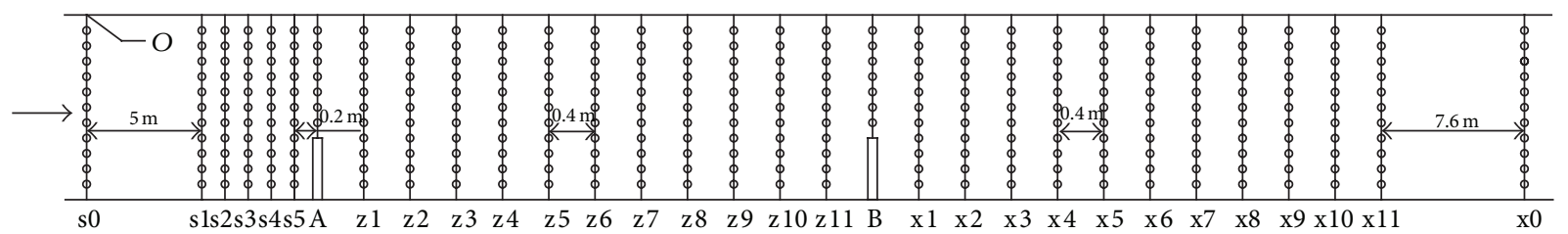

(a) Ipsilateral layout

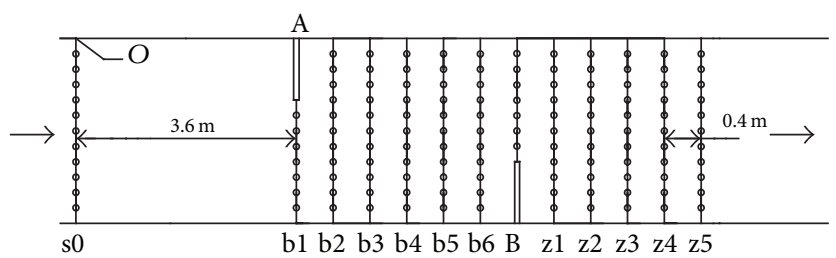

(b) Alternate layout

FIGURE 2: Spur dike layouts, monitoring cross sections, and monitoring points.

(FVM), and the rigid lid assumption was verified by observed data and employed to investigate the spacing threshold of alternate spur dikes.

\section{Materials and Methods}

2.1. Flume Experiments. The multifunction flume used in this study is $50 \mathrm{~m}$ long, $1.2 \mathrm{~m}$ wide, and $1.4 \mathrm{~m}$ deep, with a concrete floor and two toughened glass sidewalls. It is located in Jiangong, Test Hall of Zhejiang University, China, as shown in Figure 1. The longitudinal slope of the flume is zero. The spur dikes are made of plexiglass being $1.6 \mathrm{~cm}$ thick and $40 \mathrm{~cm}$ high, which are installed on the vertical walls of flume by slots. A three-dimensional ADV (Acoustic Doppler Velocimeter) probe is employed to measure the underlying velocity field, and WHR (wave height recorder) is utilized for bathymetry.
They are both shown in Figure 1. There are two kinds of the layouts of spur dikes (namely, ipsilateral and alternate) shown in Figure 2. The spur dikes 1,2 and the inlet are placed at sections $\mathrm{A}, \mathrm{B}$, and $\mathrm{s} 0$, respectively. In the ipsilateral layout (Figure 2(a)), the flow velocity is recorded at 5 cross sections on the upstream of spur dike 1 with equal interval of $0.2 \mathrm{~m}$, 11 (z1-z11) between spur dike 1 and spur dike 2 with equal interval of $0.4 \mathrm{~m}$, and 11 (x1-x11) on the downstream of spur dike 2 with equal interval of $0.4 \mathrm{~m}$. The outlet is placed at section $\mathrm{x} 0$ with $7.6 \mathrm{~m}$ from section $\mathrm{x} 11$. There are totally 31 monitoring cross sections with 341 points in the whole test region. In the alternate layout (Figure 2(b)), there are 10 cross sections (b2-z4) between b1 and $\mathrm{z} 5$ with equal interval of $0.4 \mathrm{~m}$. The original coordinate is set at the point $O$ at the bottom of flume as shown in Figure 2. The direction along the mainstream is $X$, along the water depth is $Y$, and along the axis of spur dike is $Z$. 
TABLE 1: Verification conditions.

\begin{tabular}{|c|c|c|c|c|c|}
\hline No. & Category & $\begin{array}{l}\text { Flow rate } \\
Q\left(\mathrm{~m}^{3} / \mathrm{s}\right)\end{array}$ & $\begin{array}{c}\text { Dike length } \\
B(\mathrm{~m})\end{array}$ & $\begin{array}{c}\text { Water depth } \\
h(\mathrm{~m})\end{array}$ & $\begin{array}{c}\text { Dike spacing } \\
s(\mathrm{~m})\end{array}$ \\
\hline $\mathrm{vl}$ & Ipsilateral & 0.0416 & 0.4 & 0.15 & 4.8 \\
\hline v2 & Alternate & 0.0603 & 0.4 & 0.3 & 2.4 \\
\hline
\end{tabular}

\subsection{Numerical Model}

2.2.1. Model Construction and Boundary Conditions. The commercial computational fluid dynamics (CFD) code, FLUENT, is chosen to build the numerical model. Several auxiliary surfaces are added to divide the calculation area into regular blocks. Hexahedral structured meshes are adopted and refined in the vicinity of spur dikes. In our past research [18], three turbulence models, that is, the standard $k-\varepsilon$ model, the Reynolds stress model (RSM), and the large eddy simulation (LES) model, were used to simulate the flow field of nonsubmerged spur dikes. In each model, the free surface boundary was implemented by two approaches, that is, the rigid lid assumption and the volume of fluid (VOF) method. The results showed that the standard $k-\varepsilon$ model combined with the rigid lid assumption was most efficient among all the combinations and it is used in this study.

The pressure-based solver in FLUENT is used. The hydraulic diameter $D_{H}$ and the turbulence intensity $I$ are selected as turbulence parameters, expressed in (1) and (2), respectively [19]:

$$
\begin{gathered}
D_{H}=\frac{2 A}{C}, \\
I=0.16\left(R_{e}\right)^{-1 / 8},
\end{gathered}
$$

where $A$ is the cross section area; $C$ is the wetted perimeter; $R_{e}$ is the Reynolds number associated with $D_{H}$.

The pressure-velocity coupling is achieved by SIMPLIC (semi-implicit method for pressure-linked equations consistent). The body force weighted method is used for pressure discretization and the first-order upwind method for the discrete format of momentum, turbulent kinetic energy, and turbulent dissipation rate. For boundary conditions, the mass-flow-inlet is used for approaching flow at the inlet, the outflow at the outlet, no-slip walls for the vertical and bottom faces of flume and dike bodies, and standard wall functions for the solution of $k, \varepsilon$ near walls. The rigid lid assumption takes the free surface as constant, and the top face of water body is assumed to be symmetric. Compared with the wall treatment method, the tangential velocity on the free surface may not be zero.

2.2.2. Model Verification. To verify the numerical model, two sets of experimental conditions, that is, ipsilateral (v1) and alternate (v2), listed in Table 1 are chosen. s5, z1, z6, z11, xl, and $\mathrm{x} 0$ cross sections are selected for ipsilateral spur dikes and b1, b4, B, and z3 for alternative spur dikes. Since the velocities of mainstream ( $X$ direction) are dominant and the velocities in $Y$ and $Z$ directions are very small, only the velocities in $X$ direction $(u)$ are verified. Figure 3 compares the observed and computed velocity in $X$ direction along $Z$ on a horizontal plane under $\mathrm{v} 1$ and $\mathrm{v} 2$ conditions. It is clearly revealed that the computed velocities agree well with the observed under both conditions. Therefore, the numerical model is accurate and can be used for the following analyses.

2.3. Dimensional Analysis. Since the spur dike flow is regarded as fully turbulent, viscous effects (i.e., Reynolds number effects) can be neglected [20]. The dike thickness is $0.016 \mathrm{~m}$, which is insignificant for dike spacing. Hence, the dimensional analysis suggests the following functional relationship for the spacing threshold $\left(S_{c}\right)$ of nonsubmerged double spur dikes with alternate layout and same length in straight rectangular channel:

$$
S_{c}=f(\rho, g, Q, h, b, B),
$$

where $B$ is channel width; $b$ is dike length; $Q$ is the flow rate of approaching flow; $h$ is water depth. According to $\pi$ theorem, $\rho, g$, and $h$ are selected as the basic parameters. Dimensionless equations are further deduced in

$$
\begin{gathered}
\frac{S_{c}}{b}=f\left(F_{r}, \frac{B}{h}, \frac{B}{b}\right), \\
F_{r}=\frac{Q}{B h \sqrt{g h}} .
\end{gathered}
$$

Based on (4), 15 conditions, listed in Table 2, are simulated. In cl to c5, $Q$ is varied in five steps from $0.0336 \mathrm{~m}^{3} / \mathrm{s}$ to $0.2352 \mathrm{~m}^{3} / \mathrm{s}$ leading to a variable $F_{r}$ ranging from 0.1 to 0.7 with constant $B / h=6$ and $B / b=6$. In $c 6$ to $c 10, B / b$ is varied from 2.4 to 12 with constant $F_{r}=0.2$ and $B / h=6$. In cll to $c 15, B / h$ is varied from 2 to 12 with constant $F_{r}=0.2$ and $B / b=6$. To exclude the interference of channel length on the spur dike field, the length of numerical flume is taken as $100 \mathrm{~m}$ after several trials.

\section{Results and Discussion}

3.1. Spacing Thresholds. In our past research [8], we have proposed the definition of spacing threshold of nonsubmerged double spur dikes with ipsilateral layout and same length in straight rectangular channel, that is, the spacing when lateral distributions of velocities at adjacent two spur dike sections become coincided. For simplicity, the depthaveraged velocity $(\bar{u})$ near adjacent two spur dike tips can be used as an alternative criterion $[8,18]$. For alternate spur dikes, the threshold value should be redefined as the spacing when the lateral distribution of velocities at adjacent two spur dike sections becomes just coincided in reverse direction, while the criterion for the ipsilateral spur dikes 


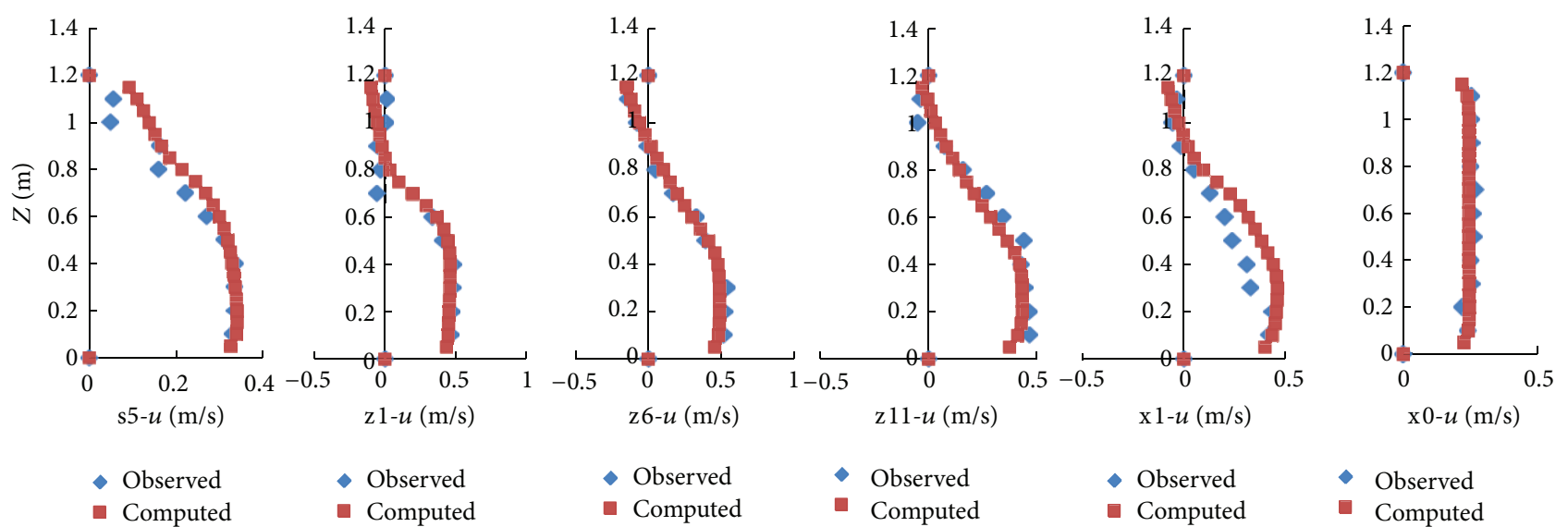

(a) vl at horizontal plane $Y=0.16 \mathrm{~m}$
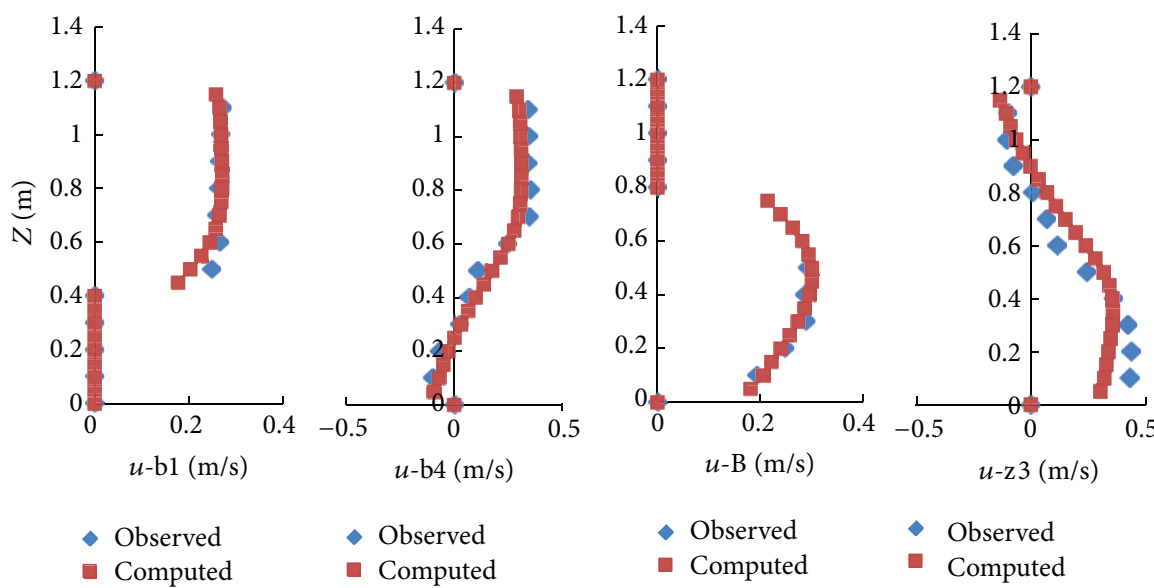

(b) v2 at horizontal plane $Y=0.09 \mathrm{~m}$

FiguRE 3: Comparison of $u$ between observed and computed values.

TABLE 2: Simulation conditions.

\begin{tabular}{lcccccc}
\hline No. & $B(\mathrm{~m})$ & $b(\mathrm{~m})$ & $h(\mathrm{~m})$ & $Q\left(\mathrm{~m}^{3} / \mathrm{s}\right)$ & $F_{r}$ & $B / h$ \\
\hline c1 & 1.2 & 0.2 & 0.2 & 0.0336 & 0.1 & 6 \\
c2 & 1.2 & 0.2 & 0.2 & 0.0672 & 0.2 & 6 \\
c3 & 1.2 & 0.2 & 0.2 & 0.1008 & 0.3 & 6 \\
c4 & 1.2 & 0.2 & 0.2 & 0.168 & 0.5 & 6 \\
c5 & 1.2 & 0.2 & 0.2 & 0.2352 & 0.7 & 6 \\
c6 & 1.2 & 0.5 & 0.2 & 0.0672 & 0.2 & 6 \\
c7 & 1.2 & 0.4 & 0.2 & 0.0672 & 0.2 & 6 \\
c8 & 1.2 & 0.3 & 0.2 & 0.0672 & 0.2 & 6 \\
c9 & 1.2 & 0.2 & 0.2 & 0.0672 & 0.2 & 6 \\
c10 & 1.2 & 0.1 & 0.2 & 0.0672 & 0.2 & 6 \\
c11 & 0.6 & 0.1 & 0.3 & 0.0618 & 0.2 & 6 \\
c12 & 1.2 & 0.2 & 0.3 & 0.1235 & 0.2 & 6 \\
c13 & 1.2 & 0.2 & 0.2 & 0.0672 & 0.2 & 6 \\
c14 & 1.8 & 0.3 & 0.2 & 0.1009 & 6 & 6 \\
c15 & 2.4 & 0.4 & 0.2 & 0.1345 & 6 \\
\hline
\end{tabular}

Note: c2, c9 and c13 are identical. 


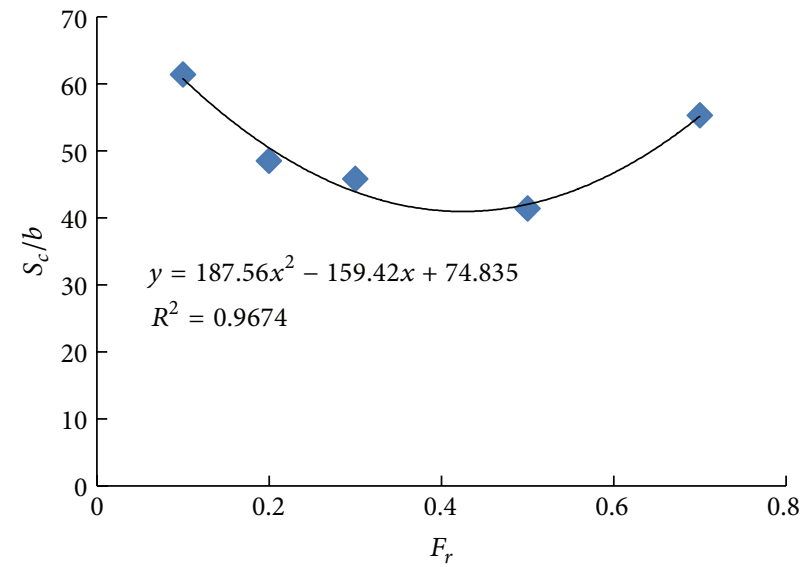

(a) $S_{c} / b \sim F_{r}(B / h=6$ and $B / b=6)$

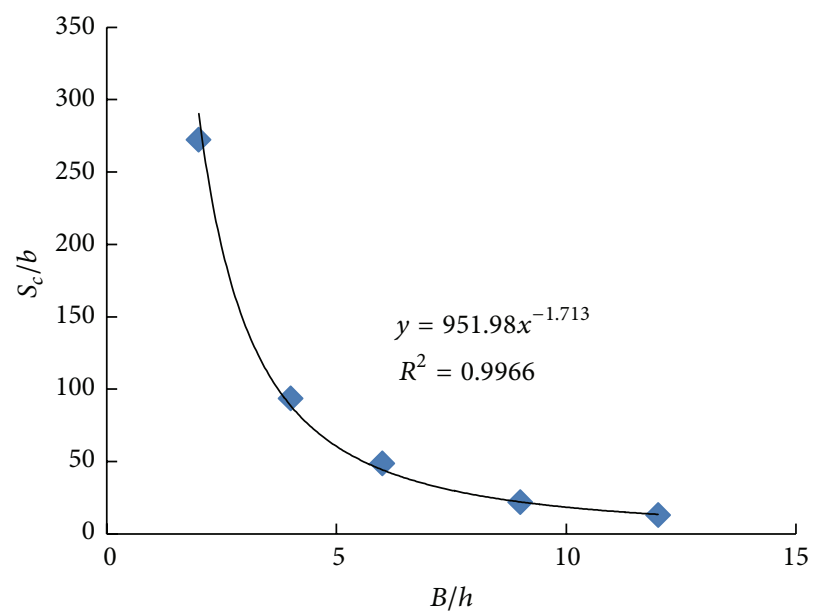

(c) $S_{c} / b \sim B / h\left(F_{r}=2\right.$ and $\left.B / b=6\right)$

FIGURE 4: Variation of $S_{c} / b$ with $F_{r}, B / b$ and $B / h$.

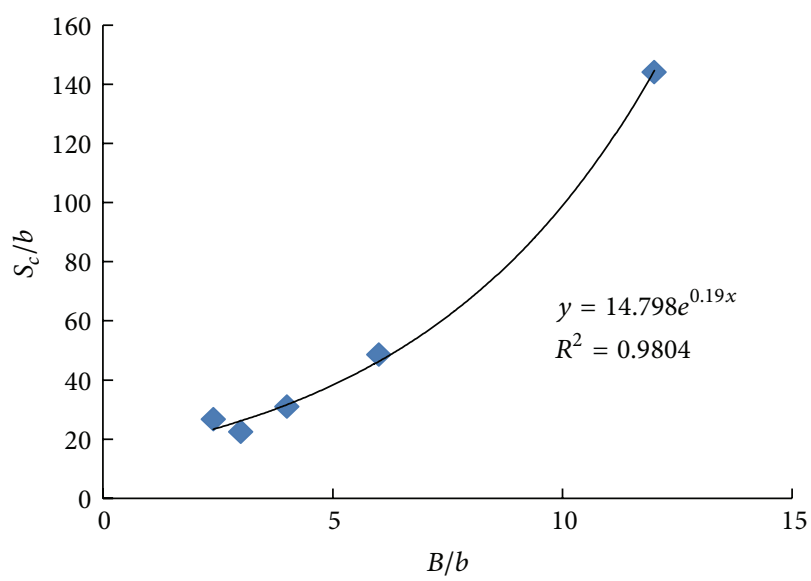

(b) $S_{c} / b \sim B / b\left(F_{r}=2\right.$ and $\left.B / h=6\right)$ is still applicable. After the flow passes a spur dike, the disturbance reduces gradually but does not disappear. It is assumed that, when the velocity difference $\Delta u$ reaches $k u_{0}(k$ is a constant and less than 1 and here is 0.01 ), the velocities at spur dike 2 are considered recovered [21]. Spur dike 1 is placed at $X=26 \mathrm{~m}$ and the spacing thresholds are searched by changing the location of spur dike 2 . Table 3 lists the spacing threshold $S_{c}$ and dimensionless parameter $S_{c} / b$ of cl-c15.

3.2. Multivariate Dimensionless Regression. According to the data in Table 3 , the variations of $S_{c} / b$ with $F_{r}, B / b$ and $B / h$ are shown in Figures 4(a), 4(b), and 4(c), respectively. It is clear that when $B / h$ and $B / b$ are maintained, $S_{c} / b$ decreases first and then increases as $F_{r}$ increases, and the minimum of $S_{c} / b$ arises at around $F_{r}=0.4$. The relationship between $S_{c} / b$ and $F_{r}$ is a quadratic function with an upward opening. When $F_{r}$ and $B / h$ are fixed, $S_{c} / b$ increases monotonically as $B / b$ increases, and the increase rate of $S_{c} / b$ is firstly slow and then rapid. The relationship between $S_{c} / b$ and $B / b$ is approximately an exponential function. When $F_{r}$ and $B / b$ are
TABle 3: Spacing thresholds of cl-cl5.

\begin{tabular}{lcc}
\hline No. & $S_{c}(\mathrm{~m})$ & $S_{c} / b$ \\
\hline c1 & 12.273 & 61.365 \\
c2 & 9.699 & 48.495 \\
c3 & 9.154 & 45.770 \\
c4 & 8.271 & 41.355 \\
c5 & 11.056 & 55.280 \\
c6 & 13.330 & 26.660 \\
c7 & 8.982 & 22.455 \\
c8 & 9.280 & 30.933 \\
c9 & 9.699 & 48.495 \\
c10 & 14.402 & 144.020 \\
c11 & 27.214 & 272.140 \\
c12 & 18.667 & 93.335 \\
c13 & 9.699 & 48.495 \\
c14 & 6.545 & 21.817 \\
c15 & 5.059 & 12.648 \\
\hline
\end{tabular}


TABLE 4: Testing conditions.

\begin{tabular}{lccccccc}
\hline No. & $B(\mathrm{~m})$ & $b(\mathrm{~m})$ & $h(\mathrm{~m})$ & $Q\left(\mathrm{~m}^{3} / \mathrm{s}\right)$ & $F_{r}$ & $B / h$ \\
\hline $\mathrm{t} 1$ & 1 & 0.2 & 0.25 & 0.1566 & 0.4 & 4 \\
$\mathrm{t} 2$ & 1.5 & 0.15 & 0.2 & 0.1051 & 0.25 & 7.5 \\
$\mathrm{t} 3$ & 3 & 0.75 & 0.2 & 0.7564 & 0.9 & 10 \\
$\mathrm{t} 4$ & 3 & 0.2 & 0.3 & 0.1235 & 0.08 & 15 \\
\hline
\end{tabular}



FIgURE 5: Results of the regression analysis.

maintained, $S_{c} / b$ decreases monotonically as $B / h$ increases, and when $B / h$ is smaller than 5 , the falling speed of $S_{c} / b$ is very fast, and then it becomes smooth. The relationship between $S_{c} / b$ and $B / h$ follows a power function. In addition, it also appears that among the three influencing factors, $B / h$ is the most influencing parameter on $S_{c} / b$, followed by $B / b$ and $F_{r}$. Therefore, controlling the water depth in channel and designing the reasonable length of spur dikes can change the recovery distance of spur dike flow effectively.

The results of Figure 4 are regressed by the statistical analysis software SPSS, and the dimensionless empirical formula of the spacing threshold of nonsubmerged double spur dikes with alternate layout and same length is obtained as

$$
\begin{aligned}
\frac{S_{c}}{b}= & 187.5 F_{r}^{2}-159.4 F_{r}+14.64 e^{0.19 B / b} \\
& +875.75\left(\frac{B}{h}\right)^{-1.71}-14.69
\end{aligned}
$$

Figure 5 shows the comparison of the calculation results of $S_{c} / b$ between CFD and (5) under c1-c15. A good agreement indicates that the fitting effect of empirical formula is satisfactory. To further test the accuracy of (5) applied to other conditions, four sets of new numerical simulations ( $t 1-$ t4) listed in Table 4 are conducted by using the same model. Conditions $\mathrm{t} 1$ and $\mathrm{t} 2$ are the interpolation of $\mathrm{cl}-\mathrm{c} 15$ while $\mathrm{t} 3$ and $\mathrm{t} 4$ are extrapolated. Table 5 lists the comparison of the calculation results of $S_{c}$ between CFD and (5) under t1-t4. It can be seen that the relative error (RE) of the four conditions is less than $10 \%$, which shows that the calculation accuracy of (5) for other conditions is satisfactory. Meantime, the RE of interpolation conditions is less than that of extrapolated
TABLE 5: Comparisons of $S_{c}$ between CFD and (5) under tl-t4.

\begin{tabular}{lccc}
\hline No. & CFD $(\mathrm{m})$ & Equation $(5)(\mathrm{m})$ & RE $(\%)$ \\
\hline $\mathrm{t} 1$ & 13.868 & 14.245 & 2.72 \\
$\mathrm{t} 2$ & 12.605 & 12.448 & -1.25 \\
$\mathrm{t} 3$ & 18.566 & 16.783 & -9.60 \\
$\mathrm{t} 4$ & 48.785 & 51.212 & 4.98 \\
\hline
\end{tabular}

conditions, which reveals that the dimensionless empirical formula is more accurate for the interpolation conditions.

The dimensionless empirical formula of the spacing threshold of nonsubmerged double spur dikes with ipsilateral layout and same length is expressed in [8]

$$
\begin{aligned}
\frac{S_{c}}{b}= & 143.15 F_{r}^{2}-94.39 F_{r}+14.13 \frac{B}{b} \\
& +278.02\left(\frac{B}{h}\right)^{-0.53}-79.38
\end{aligned}
$$

Figure 6 compares the empirical formulas (5) and (6) from univariate analyses. The variation tendencies of $S_{c} / b$ with each influencing factor under the two types of spur dike layouts are similar, and $S_{c}$ of alternate spur dikes are mostly smaller than those of ipsilateral spur dikes, which indicates that the flow passing alternate spur dikes is easier to recover.

The empirical formula obtained in this paper can be used to determine the impact scale of spur dikes in straight and rectangular channel. Meanwhile, the empirical formula can be used to find the recovery section of velocities at the downstream of spur dike, and it can be also used for solving the local head loss of spur dike [16]. In addition, the empirical formula lays a foundation for the research of cumulative effect of large-scale spur dikes on the river system. However, due to the assumptions used in the paper, it has inevitable application limitations. Specifically, it is required that the shape of the two spur dikes be straight without head slope, the angle between spur dike axis and flow direction of the two spur dikes be $90^{\circ}$, and the size of the two spur dikes be the same. The channel must be straight and rectangular with zero bottom slope. It should be noted that most of the limitations can be overcome by adding corresponding parameters to the empirical formula based on additional simulations. In the future, these works will be done to perfect the empirical formula and broaden its applicability.

\section{Conclusions}

A numerical model combining the standard $k-\varepsilon$ model, FVM, and rigid lid assumption has been built in this study to 


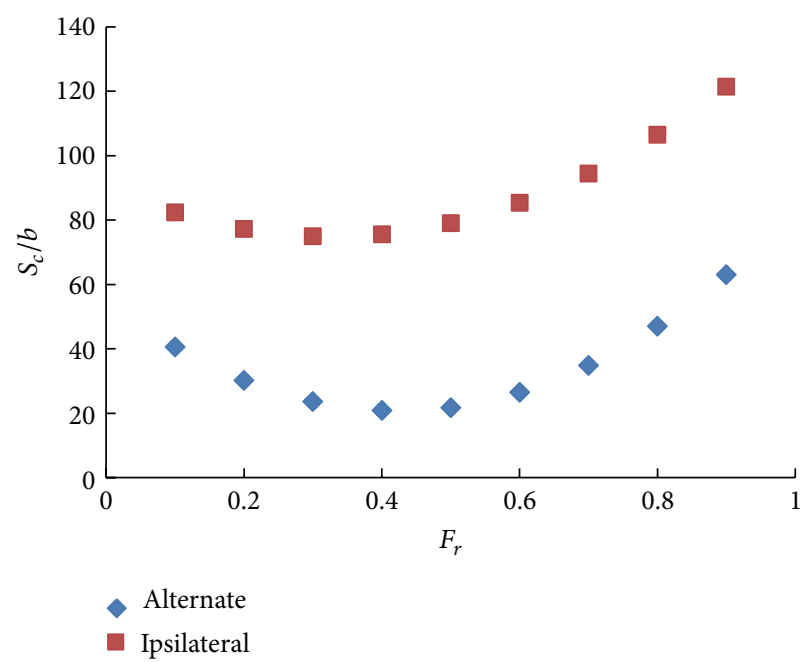

(a) $S_{c} / b \sim F_{r}(B / h=7$ and $B / b=5)$

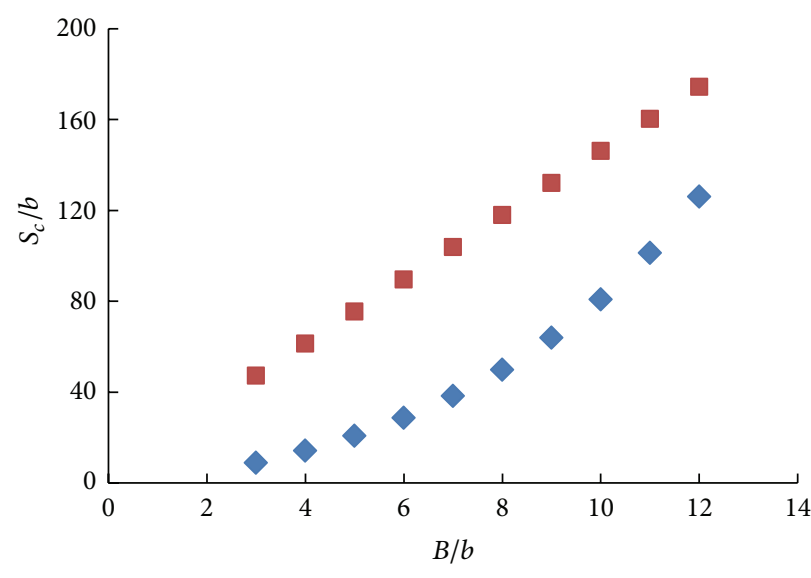

Alternate

- Ipsilateral

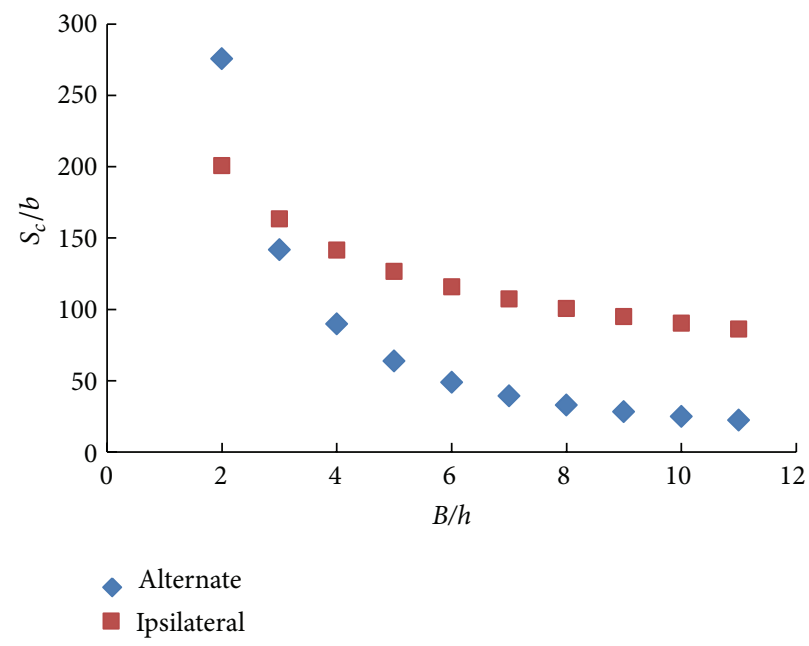

(c) $S_{c} / b \sim B / h\left(F_{r}=0.5\right.$ and $\left.B / b=7\right)$

FIgURE 6: Comparison of empirical formulas between alternate spur dikes and ipsilateral spur dikes.

investigate the spacing threshold of nonsubmerged double spur dikes with alternate layout and same length in straight rectangular channel. The main conclusions are as follows.

(1) The three influencing factors of $S_{c} / b$, that is, $F_{r}, B / b$ and $B / h$, are obtained by the dimensional analysis, and $B / h$ is the most influencing parameter on $S_{c} / b$, followed by $B / b$ and $F_{r}$.

(2) The dimensionless empirical formula of spacing threshold is obtained via multivariate regression analysis, and its accuracy is satisfactory.

(3) Compared with the spur dikes with ipsilateral layout, the spacing thresholds of alternate spur dikes are mostly smaller under the same conditions.

(4) The empirical formula proposed in this paper lays down a foundation for the research of cumulative impact of spur dikes and other river structures, for example, bridge, levee, wing-dike, navigational dam, and so forth, on river systems.

\section{Acknowledgments}

The study is supported by the National Natural Science Foundation of China (50909085, 51125034, and 51279046), the Department of Water Resources of Zhejiang Province (RC1106), and the Ministry of Water Resources of China (201101027).

\section{References}

[1] T. Ohmoto, R. Hirakawa, and N. Koreeda, "Effects of water surface oscillation on turbulent flow in an open channel with a series of spur dikes," in Proceedings if the Hydraulic Measurements and Experimental Methods, pp. 1-10, August 2002.

[2] J. G. Duan, L. He, X. Fu, and Q. Wang, "Mean flow and turbulence around experimental spur dike," Advances in Water Resources, vol. 32, no. 12, pp. 1717-1725, 2009.

[3] X. Zhang, P. Wang, and C. Yang, "Experimental study on flow turbulence distribution around a spur dike with different structure," in Proceedings of the International Conference on 
Modern Hydraulic Engineering (CMHE '12), vol. 28, pp. 772-775, Chongqing, China, March 2012.

[4] R. A. Kuhnle, Y. Jia, and C. V. Alonso, "Measured and simulated flow near a submerged spur dike," Journal of Hydraulic Engineering, vol. 134, no. 7, pp. 916-924, 2008.

[5] A. Y. Ha, G. D. Li, L. Yang, and G. Chen, "Local flow field and scour near the water intake project between spur dikes," Journal of Basic Science and Engineering, vol. 20, no. 4, pp. 602-611, 2012 (Chinese).

[6] Q. Ying and Z. B. Jiao, Hydraulics of Spur Dike, Ocean Press, Beijing, China, 2004 (Chinese).

[7] X. D. Xu, Study on flow characteristics and impact scale of nonsubmerged orthogonal double spur dikes [M.S. thesis], Zhejiang University, Zhejiang, China, 2013 (Chinese).

[8] Z. H. Gu, X. M. Cao, H. W. Tang, and X. D. Xu, "Investigation on spacing threshold of non-submerged double spurdikes with ipsilateral layout and same length".

[9] F. T. Chang and W. Feng, "Experiment at investigation of reasonable spacing among spur dikes," Journal of Hohai University, vol. 20, no. 4, pp. 7-14, 1992 (Chinese).

[10] W. Volker, A. S. Scott, and H. J. Gerhard, "Experiments on mass exchange between groin fields and main stream in rivers," Journal of Hydraulic Engineering, vol. 134, no. 2, pp. 173-183, 2008.

[11] X. G. Gao, H. F. Liu, G. F. Hua, and Z. Wang, "Rational spacing characters of double permeable spur," Journal of Shihezi University, vol. 28, no. 5, pp. 614-617, 2010 (Chinese).

[12] M. Vaghefi, M. Ghodsian, and S. Neyshabouri, "Experimental study on scour around a T-shaped spur dike in a channel bend," Journal of Hydraulic Engineering, vol. 138, no. 5, pp. 471-474, 2012.

[13] N. Pinter, A. A. Jemberie, J. W. F. Remo, R. A. Heine, and B. S. Ickes, "Cumulative impacts of river engineering, Mississippi and lower Missouri Rivers," River Research and Applications, vol. 26, no. 5, pp. 546-571, 2010.

[14] A. S. Mahiny and K. C. Clarke, "Simulating hydrologic impacts of urban growth using SLEUTH, multi criteria evaluation and runoff modeling," Journal of Environmental Informatics, vol. 22, no. 1, pp. 27-38, 2013.

[15] Y. Yang and H. Chen, "Assessing impacts of flow regulation on trophic interactions in a wetland ecosystem," Journal of Environmental Informatics, vol. 21, no. 1, pp. 63-67, 2013.

[16] P. J. Yue, W. S. Li, and X. G. Yang, "Length of whirlpool flow behind dikes," Journal of Waterway and Harbor, vol. 2, pp. 3-9, 1999 (Chinese).

[17] Y. Z. Feng and F. T. Chang, "Interaction between alternate groins in water flow," Journal of Hohai University, vol. 24, no. 1, pp. 7076, 1996 (Chinese).

[18] Z. H. Gu, X. M. Cao, and W. Z. Jane Lu, "Appropriate CFD models for simulating flow around spur dike group".

[19] A. Karvinen and H. Ahlstedt, "Computation of turbulence models in case of three-dimensional diffuser," in Proceedings of the Open Source CFD International Conference, 2008.

[20] H. Azinfar and J. A. Kells, "Backwater prediction due to the blockage caused by a single, submerged spur dike in an open channel," Journal of Hydraulic Engineering, vol. 134, no. 8, pp. 1153-1157, 2008.

[21] Q. Ying, "Flow pattern near the submerged spur dike," Journal of Hohai University, vol. 23, no. 4, pp. 62-68, 1995 (Chinese). 


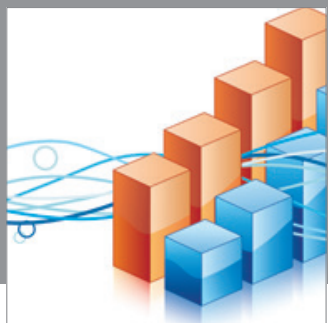

Advances in

Operations Research

mansans

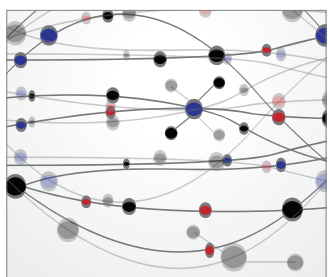

The Scientific World Journal
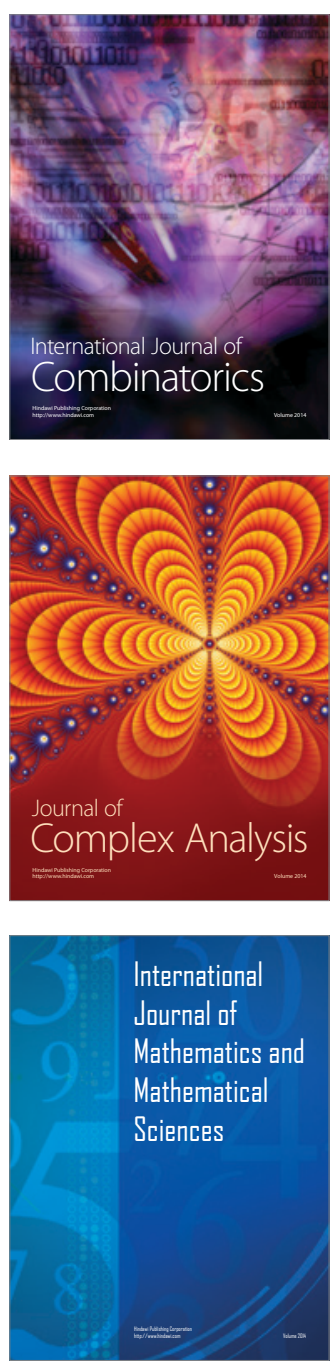
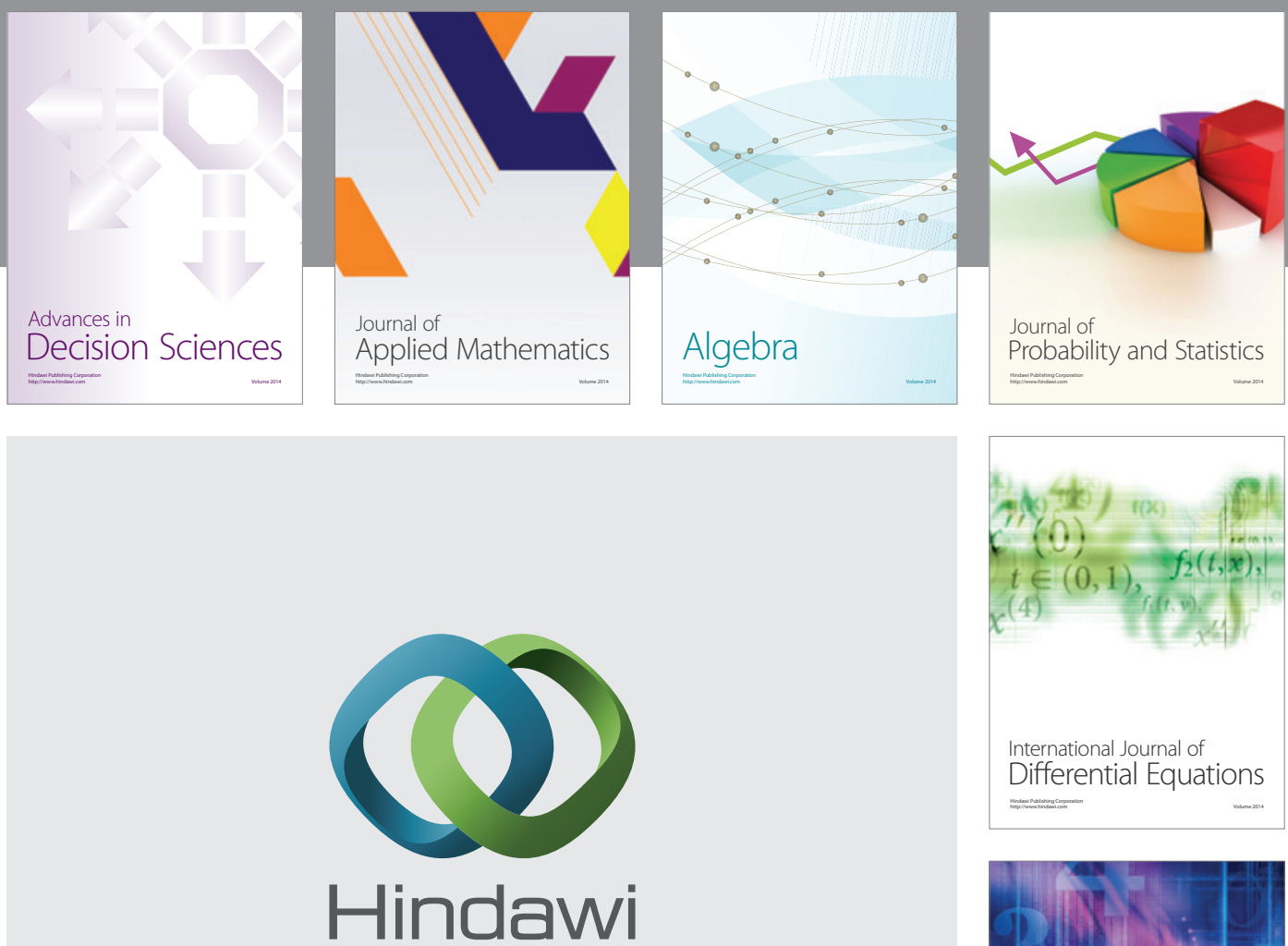

Submit your manuscripts at http://www.hindawi.com
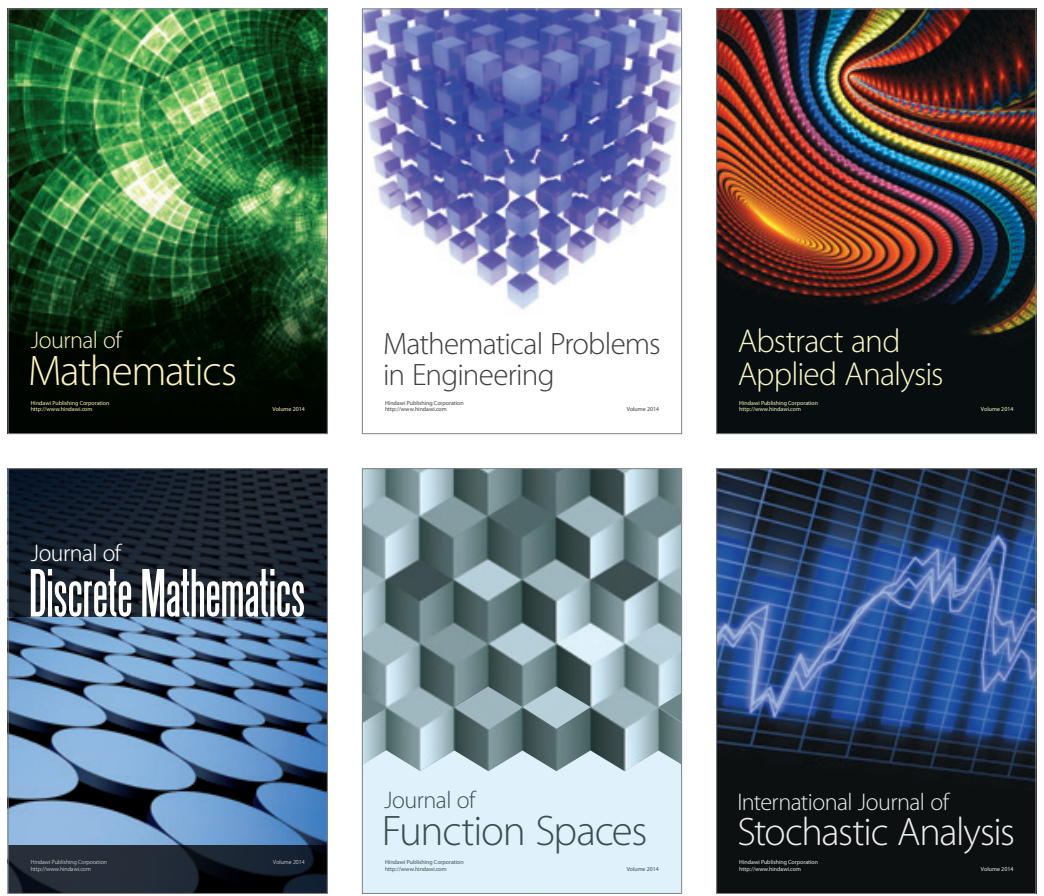

Journal of

Function Spaces

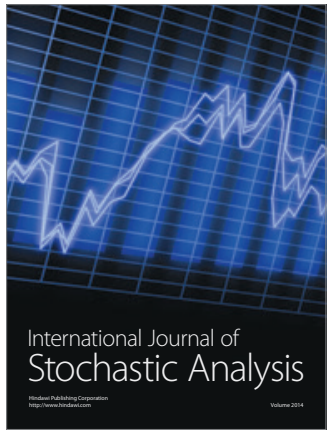

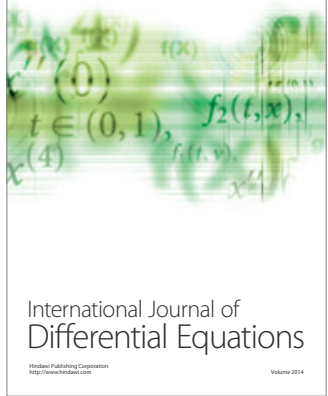
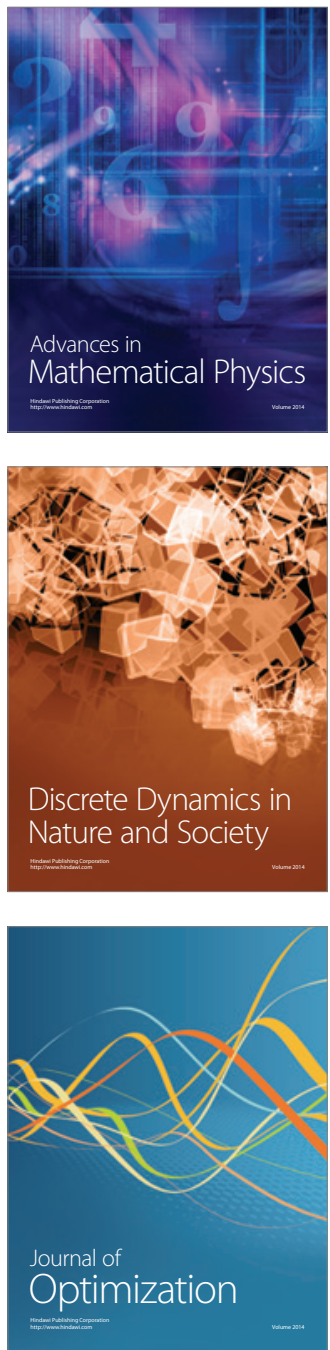